\title{
Modeling of strain and filtration properties of a semi-finished leather product
}

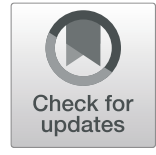

\author{
A. Amanov ${ }^{1,2 *}$, S. R. Khurramov ${ }^{3}$, G. A. Bahadirov ${ }^{3}$, A. Abdukarimov ${ }^{3}$ and T. Y. Amanov ${ }^{3}$
}

\begin{abstract}
A study on deformation and filtration properties of a leather semi-finished product after chrome tanning are presented. The analytical dependences of compressive load on compressive (recovery) strain and moisture content of a leather semi-finished product are obtained. The empirical dependences of hydraulic gradient on filtration rates are determined for various compression ratios of the leather semi-finished product. It was revealed that with an increase in compressive load and moisture content of the leather semi-finished product, the compressive deformation increases. The shoulder section is subject to the greatest deformation, then the belly section and the least deformation is observed in the butt section. A linear relationship has been established between the hydraulic gradient and the rate of moisture filtration through the leather semi-finished product in the directions perpendicular and parallel to its surface.
\end{abstract}

Keywords: Semi-finished leather product, Strain properties, Filtration properties, Mathematical models of leather filtration properties, Mathematical models of leather strain patterns

\section{Introduction}

The leather manufacturing involves a number of unit operations, where the liming processes decide the quality of leathers [1]. It is not easy to produce a leather semifinished product because of complex process parameters and various chemicals involved in leather making processes in terms of mechanics as well as chemistry. Therefore, tanners are directed to follow sustainable leather-technologies to reduce the pollution problems. In addition, the unhairing and liming operations result in $60-70 \%$ of the total pollution load in the leather industry [2]. With the aim of reducing a leather semifinished product production cost and a pressure of various treatments the optimization of the conditions in the processes and theoretical models are still necessary. In order to understand the influencing mechanism of

\footnotetext{
* Correspondence: amanov_a@yahoo.com

'Department of Mechanical Engineering, Sun Moon University, Asan, Republic of South Korea

${ }^{2}$ Department of General Engineering Disciplines, Faculty of Agricultural Mechanization, Tashkent Institute of Irrigation and Agricultural Mechanization Engineers, Tashkent, Uzbekistan

Full list of author information is available at the end of the article
}

various factors such as strain, filtration, etc. of the semifinished product leather it is necessary to investigate the development of theoretical models. Nowadays, a high number of efforts have been made to the improvement of the quality of the leather semi-finished products. For example, Moktadir et al. developed a model for the sustainable supply chain management in leather industry [3]. Another study reported that a kinematic model of chrome tanned leather [4]. An important and crucial place in the technology of leather mechanical processing occupies the water squeezing from a leather semi-finished product, performed mainly by rollers. A theoretical description of the process of rolling of a leather is one of the most difficult tasks in modern mechanics. It is essential to find a joint solution to two tasks: the first one is the contact interaction in two-roll modules (the contact task); the second one is the moisture filtration in a deformable inhomogeneous porous medium (the hydrodynamic problem). The leather is pressed after tanning. In this regard, the paper considers the problems of analytical description of the deformation and filtration properties of semi-finished leather after tanning, with the aim of their further use in modeling the roll pressing of leather. Over a decade and more now, 
the researchers have been focusing on sustainability-based research goals and objectives for the leather semifinished product. Several sustainable technologies addressed to each unit operation during leather processing have been developed and showcased. Moreover, there are a lot of publications devoted to physico-mechanical properties of a leather semifinished product $[5,6]$. However, only a few publications have been devoted to the study of deformation properties of a leather semi-finished product after chrome tanning. Graphical characteristics of deformation properties of a leather semi-finished product after chrome tanning under compression were given elsewhere [7]. The "stress-strain" dependences of chrome tanned leather under compression were established earlier, but it is insufficient to describe the strain nature of a leather semi-finished product by mathematical formulas. The strain behavior of a leather semi-finished product after tanning under compression and recovery was specified based on models described [8]. The deformation properties of semifinished leather after tanning was reported in our previous papers $[9,10]$, which provided a detailed analysis of the literature on the deformation properties of semi-finished leather products. Therefore, we present some additional information from the literature on this issue.

To simulate the processes of contact interaction, the strain models of "stress-strain" type of the leather semifinished product are necessary. Hence, the dependences of the form can be as follows [11]:

$$
\sigma=\sigma(\varepsilon)
$$

The previously obtained dependence,

$$
\sigma=a+b \varepsilon+c \varepsilon^{2}+d \varepsilon^{3}
$$

where the coefficients characterizing the topographic features of the semi-finished leather product [9] were used in the study of the roller pressing of the semifinished leather product with vertical feeding.

As a result of analysis of experimental studies of the stress-strain curves of a leather semi-finished product after tanning under compression, it was recommended to divide each curve into four regions described by different formulas: the first and the last ones - by linear dependencies, the second and the third ones - by power dependencies [12]. A "strain-stress" dependence of the strain properties of a leather semi-finished product was given by formula $[13,14]$ :

$$
\varepsilon=A Q^{n}
$$

where $\varepsilon$ - is the strain; $Q$ - is the stress; $A, n$ - are the empirical coefficients.
It is suggested that $A=0.103 W+1.44$, for leather upper shoes, where: $W$ - is the leather moisture content [13]. A formula of the following form was given [14]:

$$
\varepsilon(\sigma, \tau, W)=a\left(0,47 \sigma^{0.243}+0.275 \tau^{0.05}-0.273\right)\left(\frac{W}{73}\right)^{2.31}+b
$$

for a leather semi-finished product after chrome tanning, where: $\varepsilon$ - is the strain, $\tau$ - is the time of load impact, is the leather moisture content, $\sigma-$ is the compressive stress, $a, b$-are the coefficients characterizing the topographic features of the leather semi-finished product.

Filtration properties of materials are characterized by the relationship between hydrostatic pressure and fluid filtration rate. Currently, there are no data characterizing the filtration properties of semi-finished leather in the literature. Thus, at present, there are no analytical dependencies that describe the deformation and filtration properties of a semi-finished tanning product after tanning, which can be used in solving contact and hydrodynamic problems of the process of roller pressing of leather. Hence, the purpose of this study is to develop a model for the deformation and filtration of a leather semi-finished product. Based on the analysis of previous publications, it was concluded that the modeling the strain pattern of the leather semi-finished product under compression and recovery and the simulation of the filtration properties of the leather semi-finished product.

\section{Experimental studies}

\subsection{Study of deformation properties of a leather semi- finished product}

One of the most important problems is to determine the analytical equation reflecting the shape of the contact curve. The shape of the roll contact curves is judged by the change in material layer thickness along the roll contact zone. The experiments were carried out using a facility shown in Fig. 1 . The operation principle of the installation is as follows: with the help of a counterweight (7), the lever (8) is set in a horizontal position, and is fixed by lifting with a limiter (9). The hemispherical head (6) abuts against the lever (8). The test sample (2) is placed on the center of the stand (1), during the rotation of which a gap is formed between the sample and the head (3), equal to the measured thickness test specimen. The necessary compressive load is created with the selection of the mass of the weight (11) and its location on the lever (8). The limiter (9) is lowered and the lever (8) presses through the head (6) on the rod (4), which, moving downward, compresses the sample (2) with the head (3) having a surface area of $1 \mathrm{~cm}^{2}$. After a set time, with the lifting of the limiter (9), the 


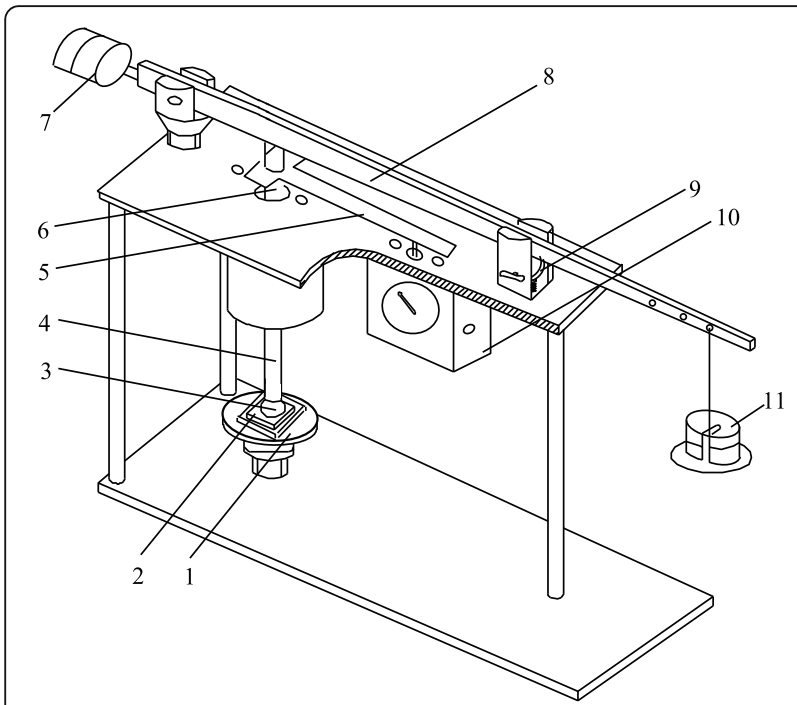

Fig. 1 Schematic view of an installation to study the strain pattern of a leather semi-finished product

compressive load is removed by lifting the cam mechanism (9). Then the sample (2) begins to recover the strain and moves the rod (4) in the opposite direction. In this case, the sample (2) is under the force $0.001 \mathrm{MPa}$. The compression and recovery deformation of the leather semi-finished product (2) is measured with a precision indicator (10) with a graduation of $0.001 \mathrm{~mm}$ using a Tshaped plate (5). In this test, two sets of stamp and head were used. The first set is designed to study the strain in a leather semi-finished product in a direction of its vertical surface, and the second - in a direction radial to the roll axis.

As shown in Figs. 2(a and b), for experimental research, semi-finished leather products were used - chrome-tanned beef from butt region, after pressing on roller squeezers, processed at the production sites of PREMIUM LEATHER LLC (Limited Liability Company) (Kokand, Fergana region, Uzbekistan). From $x=2500$ pieces of semi-finished products according to the formula $n=0.2 \sqrt{x} 10$ were selected. Based on the method of testing leather in compression, samples of size $60 \times 60$ $\mathrm{mm}^{2}$ were prepared from each selected semi-finished product and assembled into groups [9]. The tests were performed at a load of 2 to $10 \mathrm{MPa}$, a moisture of 0.8 to 1.0 (from 60 to $75 \%$, respectively), a time of compression load impact for $1 \mathrm{~min}$.

\subsection{Study of filtration properties of a leather semi- finished product}

A characteristic feature of filtration during squeezing is the significant compression of the leather semi-finished product during the moisture movement in its pores. Depending on the degree of compression of the material, its filtration characteristics also change. In this regard, we studied the moisture filtration through a leather semi-finished product at various degrees of compression. The installation (see Fig. 3), on which the tests were carried out, consists of three parts: a filtration device, a press and a device for water supply. The main part of the filtration device is a base (2) - a massive hollow container, in the upper part of which, on the ring collar, metal grill (4), rubber ring, inside which the test sample (5) is, a metal grill (6) and a piston (21) are consecutively placed. On the side of the base (2), a pipe (3) is fixed, and a tube (22), from which water is drained into glass (23). In the filtering apparatus, metal grill (4), sample (5) and metal grill (6) are designed to test the water filtration through a leather semi-finished product in a
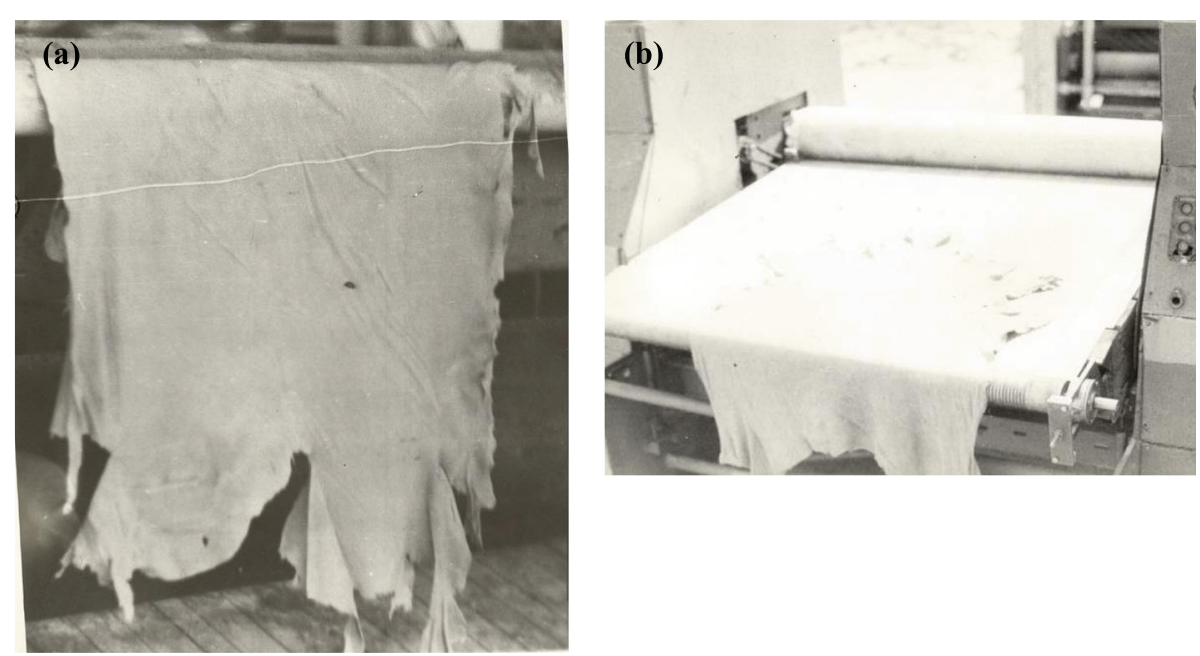

Fig. 2 Semi-finished leather product - chrome-tanned beef obtained from butt region (a), after pressing on roller squeezers (b) 


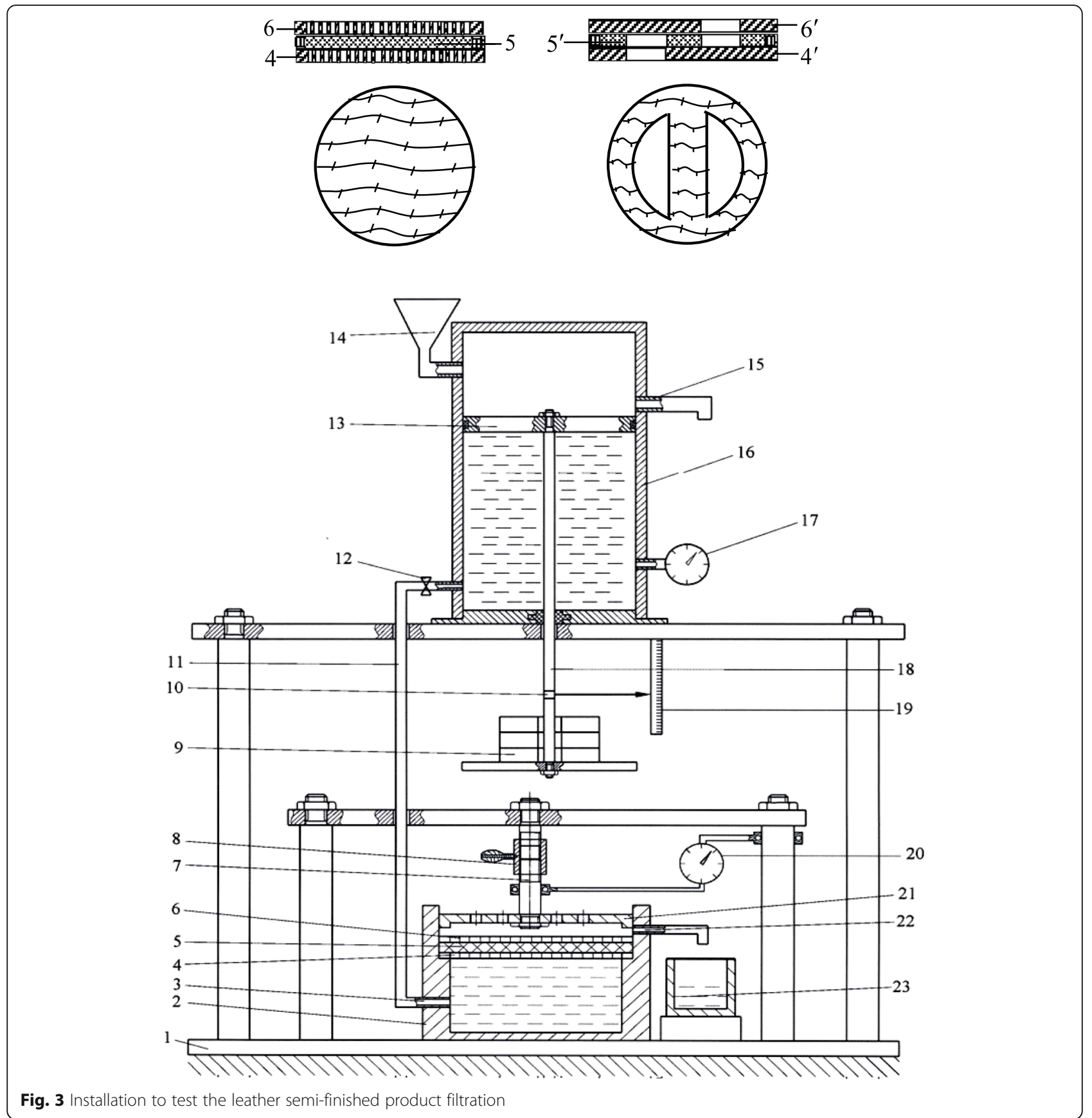

direction perpendicular to its surface. When studying the water filtration through the leather semi-finished product in a direction parallel to its surface, the metal grill (4), the sample (5) and the metal grill (6) are replaced by a metal grill $\left(4^{\prime}\right)$, a sample $\left(5^{\prime}\right)$, and a metal grill $\left(6^{\prime}\right)$, respectively.

The operation principle of the installation as follows: the filtration device is installed on the groundwork (1). The rod (7) of the press abuts against piston recess (21). Using an extension cord (8) and a precision indicator with a graduation of $0.001 \mathrm{~mm}(20)$, the required strain value of the sample (5) is set and fixed by the lock nut of extension cord (8). A branch pipe (11) of the device III is connected to a hose (3). Water is poured into cylinder (16) through a funnel (14) until it appears in tube (15). When the cylinder is filled with water, a valve (12) closes and a piston (13) is lowered until it comes into contact with water. The necessary pressure is created using a load (9) and opens a valve (12). Hydraulic pressure is determined by a pressure gauge (17), and the piston displacement is measured using a ruler (19) through a rod (18) and a plug (10). 
When studying the water filtration through a leather semi-finished product in the direction perpendicular to its surface, the samples of size $10 \mathrm{~cm}^{2}$ (of diameter 35.7 $\mathrm{mm}$ ) were prepared, and in parallel direction as shown in Fig. 3. These samples were cut and completed using the method of asymmetric fringe from bovine leather semi-finished products, processed according to the technology of chrome leather production after chrome tanning and laying. A fluid used for chrome tanning of a leather semi-finished product was taken as a filtering fluid. The relative strain of the leather semi-finished product in the tests varied from 0.314 to 0.593 , and the pressure on the cylinder was $0.05-2.13 \mathrm{MPa}$. Piston displacement and hydrostatic gradient were measured after $5,10,20,40$, and $60 \mathrm{~s}$. The reliability of the experimental results can be assured by replicating the experiments under same conditions at least three times and then the average results of three experiments may be reported. Moisture filtration rates through the leather semifinished product in the directions parallel and perpendicular to its surface and the hydraulic gradient in these directions were calculated from formulas given in [15]:

$$
\begin{gathered}
v_{x}=\frac{1}{5} \sum_{i=1}^{5} v_{x i}=\frac{1}{5} \sum_{i=1}^{5} \frac{g_{i}}{F_{x} t_{i}}, \quad v_{y}=\frac{1}{5} \sum_{i=1}^{5} v_{y i}=\frac{1}{5} \sum_{i=1}^{5} \frac{g_{i}}{F_{y} t_{i}}, \\
I_{x}=\frac{1}{5 l_{1}} \sum_{i=1}^{5}\left(\frac{\gamma}{\gamma_{B}} \sigma_{y}-\frac{S_{i}-S_{I-1}}{2}\right), \quad I_{y}=\frac{1}{5 l_{2}} \sum_{i=1}^{5}\left(\frac{\gamma}{\gamma_{B}} \sigma_{y}-\frac{S_{i}-S_{I-1}}{2}\right),
\end{gathered}
$$

where $v_{x}, v_{y^{-}}$are the filtration rates, $\mathrm{cm} / \mathrm{s} ; I_{x}, I_{y^{-}}$are the hydraulic gradients; $F_{x}, F_{y}$ - are the areas by which the filtration occurs, $\mathrm{cm}^{2} ; t_{i}$ - is the filtration duration, $s ; l_{1-}$ is the length of filtration path equal to the length of the sample jumper, $5, \mathrm{~cm} ; l_{2}-$ is the sample thickness after compression in the press $I I, \mathrm{~cm} ; \sigma_{y^{-}}$is the pressure on the cylinder, $\mathrm{cm}$ of water column; $\gamma$ - is the density of water $\mathrm{g} / \mathrm{cm}^{3} ; \gamma_{B^{-}}$is the density of the filtered moisture, equal at a temperature of $20^{\circ}$ to 1.035 , at $40^{\circ}$ to 1.020 , at $60^{\circ}$ to $1.010, \mathrm{~g} / \mathrm{cm}^{3} ; S_{i^{-}}$is the piston path in time $t_{i} \mathrm{~cm}$; $g_{i}{ }^{-}$is the amount of water filtered through the leather semi-finished product in time $t_{i}$, determined by formula $g_{i}=\frac{\pi\left(d_{y}^{2}-d_{i}^{2}\right)}{4}\left(S_{i}-S_{i-1}\right), S_{0}=0, \mathrm{~cm}^{3}$, here $d_{y}, d_{i}$ - are the diameters of the rod and cylinder, $\mathrm{cm}$.

\section{Mathematical processing of experimental results}

Deformation (filtration) properties obtained by experimental way have a direct relationship to the mathematical processing of experimental results because the reliability of the experimental data of deformation and filtration properties measuring experiments needs to be assured by using empirical formulas due to the data scattering. As a result of experiments, the obtained data showed that the relative compression and recovery strain of semi-finished leather product depends on the compression load and humidity as shown in Figs. 4 and 5 . The obtained experimental data were approximated by empirical formulas showing the dependence of compressive load on compression (recovery) strain and moisture content of the leather semi-finished product. The coefficients of empirical formulas (6)-(7) were determined by the least squares method [12, 13]. An analysis of the curves plotted according to formulas (6)-(7) shows that they are in good agreement with the experimental curves that's why there is no need to verify the correctness of the formulas. In addition, these formulas are applicable not only to the proposed experiment but also to other experiments related to the measurement of deformation and filtration properties of semi-finished leather product. The degrees of reliability and accuracy of experimental data approximation were estimated by the correlation and variation coefficients [16]. The approximation accuracy indices for these formulas are quite satisfactory, and the reliability indices are high. Therefore, we can assume that formulas (6)-(7) well describe the deformation and filtration properties of the leather semifinished product. This confirms the reliability of the developed mathematical models. Hence, those formulas can be used in solving the contact problems of the leather squeezing process by rolls. When summarizing the obtained dependences and graphs, empirical formulas were found that describe the strain of a leather semifinished product after chrome tanning in the direction vertical to its surface:

under compression

$$
\sigma=25.28 \cdot \varepsilon^{3,73} \cdot W^{-14.74}
$$

under recovery

$$
\sigma=51.80 \cdot \varepsilon^{3.55} \cdot W^{-11.88} .
$$

The graphs of dependences of moisture filtration rate through a leather semi-finished product on hydraulic gradient are shown in Fig. 6 . When summarizing the obtained dependences and graphs, empirical formulas are found that describe the filtration properties of the leather semi-finished product in directions perpendicular and parallel to its surface:

$$
\begin{aligned}
& I_{y}=\left(a_{1} \varepsilon \cdot+b_{1}\right) v_{y}, \\
& I_{x}=\left(a_{2} \varepsilon+b_{2}\right) v_{x},
\end{aligned}
$$

where $\varepsilon^{-}$is the relative strain of the leather semifinished product. The coefficients from formulas (8) and 

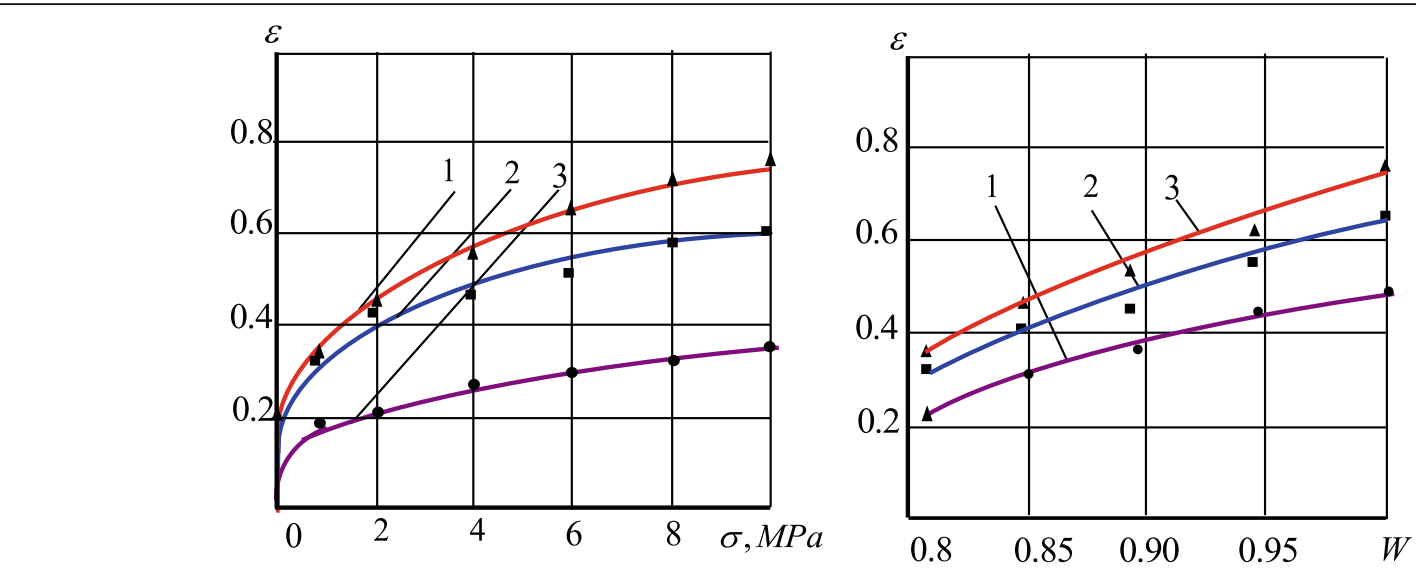

Fig. 4 Dependences of compressive strain $\varepsilon$ of the butt section on compressive load. $\sigma(1-W=1 ; 2-W=0.94 ; 3-W=0.82)$ and moisture content $W$ $(1-\sigma=10 \mathrm{MPa} ; 2-\sigma=6 \mathrm{MPa} ; 3-\sigma=2 \mathrm{MPa})$

(9), equal to $a_{1}=147 \cdot 10^{5}, b_{1}=8 \cdot 10^{4}, a_{1}=132 \cdot 10^{4}$, $b_{2}=-19 \cdot 10^{3}$, were determined by the least squares method.

An analysis of the curves plotted according to formulas (6)-(9) shows that they are in good agreement with the experimental curves. The degrees of reliability and approximation accuracy of experimental data were estimated by the correlation and variation coefficients [17]. The approximation accuracy indices for these formulas are quite satisfactory, and the reliability indices are high. For example, the coefficients of variation and correlation in formula (6), at $W=1.0$ (at moisture content $75 \%$ ) are 0.0013 and 0.995 , respectively and at $\sigma=6 \mathrm{MPa}-0.011$ and 1.005, respectively; in formula (6), at $\varepsilon=0.5$ (at relative strain $50 \%$ ) they are 0.01 and 0.99 , respectively, and at $v_{x}=10^{-4} \mathrm{~cm} / \mathrm{s}-0.033$ and 0.97 , respectively). Therefore, we can assume that formulas (8)-(9) well describe the deformation and filtration properties of the leather semi-finished product. This confirms the reliability of the developed mathematical models. Hence, they can be used in solving the contact and hydrodynamic problems of the leather squeezing process by rolls.

\section{Conclusions}

When analyzing the obtained experimental data and graphs characterizing the deformation properties of the leather semi-finished product under compression and recovery, the following aspects were revealed:

- with an increase in compressive load, the compression strain increases, and the maximum compressive strain of a butt section at a moisture content of $75 \%$ is reached under the load of $10 \mathrm{MPa}$;

- the lower the moisture content of the leather semifinished product, the less its strain. So, under compressive load of $6 \mathrm{MPa}$, the relative compressive strain of a butt section at a moisture content of $60 \%$ is 0.326 , at a moisture content of $65 \%-0.432$, at a moisture content of $70 \%-0.563$ and at a moisture content of $75 \%-0.684$, and the relative recovery
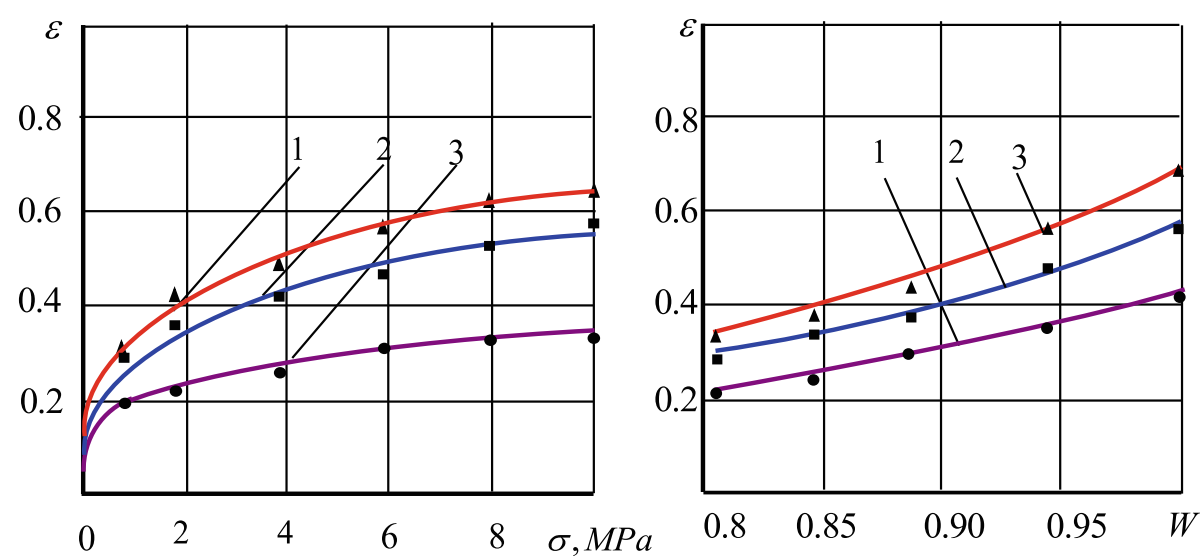

Fig. 5 Dependences of recovery strain $\varepsilon$ of the belly section on compressive load. $\sigma(1-W=1 ; 2-W=0.94 ; 3-W=0.82)$ and moisture content $W(1-\sigma=10 \mathrm{MPa} ; \sigma=6 \mathrm{MPa} ; \sigma=2 \mathrm{MPa})$ 

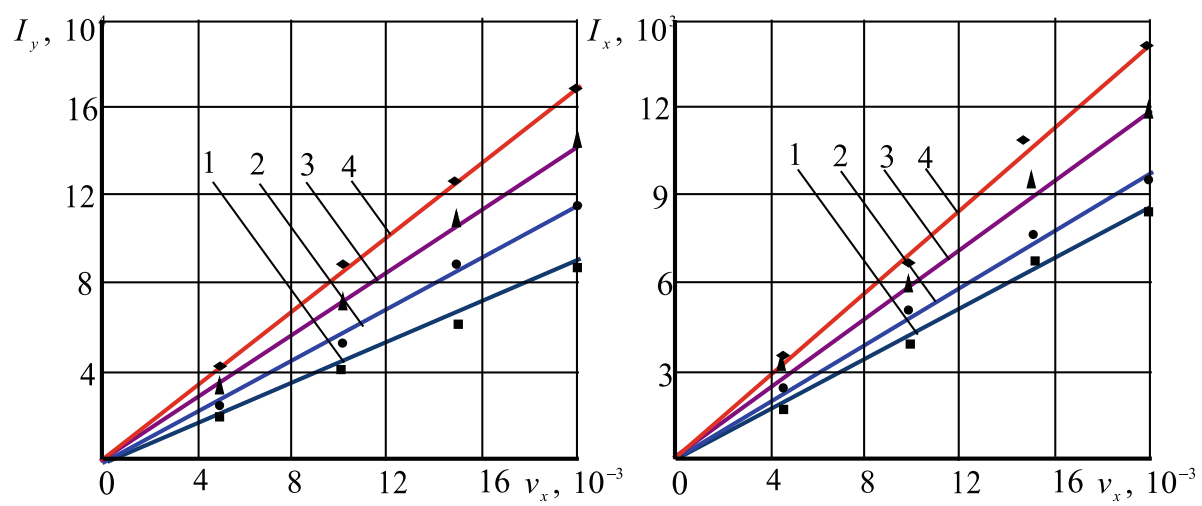

Fig. 6 Dependence of hydraulic gradients on moisture filtration rate through a leather semi-finished product, with various degrees of compression: $1-\varepsilon=0.593 ; 2-\varepsilon=0.5 ; 3-\varepsilon=0.407 ; 4-\varepsilon=0.314$

strains in these cases are $0.304,0.4010 .502$ and 0.573 , respectively;

- the compression and recovery strain curves with increasing impact time of compressive load increase sharply, then the growth slows down, and they asymptotically approach a straight line parallel to the abscissa axis;

- other conditions being equal, the greatest strains are observed in the shoulder section, then in the belly and the least ones - in the butt section;

- there are linear dependencies between the hydraulic gradient and the rate of moisture filtration through the leather semi-finished product in the directions perpendicular and parallel to its surface.

\section{Acknowledgements}

Not applicable.

\section{Authors' contributions}

A.T.A., G.A.B. and A.T.Y. designed the experiment; A.T.A. and S.R.K. performed the experiment; S.R.K., G.A.B. and A.T.Y. analyzed experimental data; A.T.A., A.A. and G.A.B. wrote the manuscript. A.T.A. reviewed and edited the manuscript. All authors read and approved the final manuscript.

\section{Funding}

This study was supported by the Industrial Technology Innovation Development Project of the Ministry of Trade, Industry and Energy, Rep. Korea (No. 20010482).

\section{Availability of data and materials}

Not applicable.

\section{Declarations}

\section{Competing interests}

The authors declare no conflict of interest.

\section{Author details}

'Department of Mechanical Engineering, Sun Moon University, Asan, Republic of South Korea. ${ }^{2}$ Department of General Engineering Disciplines, Faculty of Agricultural Mechanization, Tashkent Institute of Irrigation and Agricultural Mechanization Engineers, Tashkent, Uzbekistan. ${ }^{3}$ Institute of Mechanics and Seismic Stability of Structures named after M.T. Urazbaev of the Academy of Sciences of the Republic of Uzbekistan, Tashkent, Uzbekistan.
Received: 15 June 2020 Accepted: 21 March 2021

Published online: 15 June 2021

\section{References}

1. Liu M, Ma J, Lyu B, Gao D, Zhang J. Enhancement of chromium uptake in tanning process of goat garment leather using nanocomposite. J Clean Prod. 2016;133:487-94. https://doi.org/10.1016/j.jclepro.2016.04.156.

2. Hashem MA, Nur-A-Tomal MS, Bushra SA. Oxidation-coagulation-filtration processes for the reduction of sulfide from the hair burning liming wastewater in tannery. J Clean Prod. 2016;127:339-42. https://doi.org/10.101 6/j.jclepro.2016.03.159.

3. Moktadir MA, Ali SM, Rajesh R, Paul SK. Modeling the interrelationships among barriers to sustainable supply chain management in leather industry. J Clean Prod. 2018;181:631-51. https://doi.org/10.1016/j. jclepro.2018.01.245

4. Banon E, Marcilla A, Garcia AN, Martinez P, Leon M. Kinetic model of the thermal pyrolysis of chrome tanned leather treated with $\mathrm{NaOH}$ under different conditions using thermogravimetric analysis. Waste Manag. 2016; 48:285-99. https://doi.org/10.1016/j.wasman.2015.10.012.

5. Kozar O, Mokrousova O, Wozniak B. Deformation characteristics of leather for shoe upper, filled with natural minerals. J Chem Chem Eng. 2014;8:47-53.

6. Khurramov SR. On the theory of contact interaction in two-roll modules. Bull Univ Technol Light Ind. 2019;3:8-13 (In Russian).

7. Kozar OP, Mokrousova OR, Conoval VP, Makuska R. Deformation characteristics of genuine leather, manufactured using natural minerals. Proceedings of the $13^{\text {th }}$ International Conference "Baltic Polymer Symposium" Trakai Lithuania. 2013;9:18-21.

8. Li Z, Paudecerf D, Yang J. Mechanical behavior of natural cow leather in tension. Acta Mech Solida Sineca. 2009;22(1):37-44. https://doi.org/10.1016/ S0894-9166(09)60088-4.

9. Amanov A, Bahadirov G, Amanov TY, Tsoy G, Nabiyev A. Determination of strain properties of the leather semi-finished product and moistureremoving materials of compression rolls. Materials. 2019;12(21):3620. https:// doi.org/10.3390/ma12213620.

10. Bahadirov G, Tsoy G, Nabiev A, Umarov A. Experiments on moisture squeezing from a leather semi-finished product. Int J Recent Technol Eng. 2020;8:3367-71.

11. Khurramov SR. Some questions of the interaction theory in two-roll module. J Phys Conf Ser. 2020;546:012132. https://doi.org/10.1088/17426596/1546/1/012132.

12. Yu W. The mechanical properties of leather in relation to softness. University of Leicester, PhD Thesis, 1999.

13. Batisene MY, Mayauskene NY. Leather hardness for shoe upper. Leather Footwear Ind. 1980:9:54-5 (In Russian).

14. Amanov TY, Khurramov SR. Study of the strain pattern of the leather semifinished product under compression and recovery. Bull Univ Technol Light Ind. 1987;2:64-9 (In Russian).

15. Lomtadze VD. Physical and mechanical properties of rocks. Laboratory research methods; 1990. p. 328. (In Russian) 
16. Korotych O, Danylkovych A, Bilinskyi S, Bondarenko S. Resource-saving technologies for the production of elastic leather materials: collective monograph: Baltija Publishing; 2020. p. 418.

17. Rabinovich SG. Statistical methods for experimental data processing. Evaluating measurement accuracy: Springer; 2009.

\section{Publisher's Note}

Springer Nature remains neutral with regard to jurisdictional claims in published maps and institutional affiliations.

Submit your manuscript to a SpringerOpen ${ }^{\odot}$ journal and benefit from:

- Convenient online submission

- Rigorous peer review

- Open access: articles freely available online

High visibility within the field

- Retaining the copyright to your article

Submit your next manuscript at $\boldsymbol{\sim}$ springeropen.com 